\title{
WEIGHT-IN-MOTION ESTIMATION BASED ON RECONSTRUCTION OF TYRE FOOTPRINT'S GEOMETRY BY GROUP OF FIBRE OPTIC SENSORS
}

\author{
Alexander Grakovski, Alexey Pilipovec, Igor Kabashkin, Elmars Petersons \\ Transport and Telecommunication Institute \\ Lomonosova 1, Riga, LV-1019, Latvia \\ Phone: +37167100654.Fax:+37167100535.E-mail:avg@tsi.lv
}

\begin{abstract}
The problem of measuring road vehicle's weight-in-motion (WIM) is important for overload enforcement, road maintenance planning and cargo fleet managing, control of the legal use of the transport infrastructure, road surface protection from the early destruction and for the safety on the roads. The fibre-optic sensors (FOS) functionality is based on the changes in the parameters of the optical signal due to the deformation of the optical fibre under the weight of the crossing vehicle. A fibre-optic sensor responds to the deformation, therefore for WIM measurements it is necessary to estimate the impact area of a wheel on the working surface of the sensor called tyre footprint. This information is used further for the estimation of the vehicle wheel's speed, contact width, length, and, finally, axle's weight while in motion. Recorded signals from a truck passing over a group of FOS with various speeds and known weight are used as an input data. The results of the several laboratory and field experiments with FOS, e.g. load characteristics according to the temperature, contact surface width and loading speed impact, are provided here. The method of initial signal deconvolution on symmetric and asymmetric components provides the chance to approximate geometric size of tyre surface footprint as well as calculate weight on each wheel separately. The examples of the estimation of a truck speed, tyre contact surface footprint parameters using FOS signals are discussed in this article.
\end{abstract}

Keywords: transport telematics, weigh-in-motion, fibre-optic sensor, tyre footprint

\section{Introduction}

The worldwide problems and costs associated with the road vehicles overloaded axles are being tackled with the introduction of the new weigh-in-motion (WIM) technologies. WIM offers a fast and accurate measurement of the actual weights of the trucks when entering and leaving the road infrastructure facilities. Unlike the static weighbridges, WIM systems are capable of measuring vehicles travelling at a reduced or normal traffic speeds and do not require the vehicle to come to a stop. This makes the weighing process more efficient, and in the case of the commercial vehicle allows the trucks under the weight limit to bypass the enforcement.

There are four major types of sensors that have been used today for a number of applications comprising the traffic data collection and overloaded truck enforcement: piezoelectric sensors, bending plates, load cells and fibre-optic sensors (McCall \& Vodrazka, 1997; Teral, 1998). The fibre-optic sensors (FOS), whose working principle is based on the change of the optical signal parameters due to the optic fibre deformation under the weight of the crossing road vehicle (Batenko \& etc., 2011; Malla \& etc., 2008), have gained popularity in the last decade.

Analysis of the WIM current trends indicates that optical sensors are more reliable and durable in comparison to the strain gauge and piezoelectric sensors. Currently the two FOS types based on two main principles are being used:

- Bragg grating (the change of diffraction in a channel under deformations);

- The fibre optical properties (transparency, frequency, phase and polarization) change during the deformations.

A lot of recent investigations are devoted to the peculiarities of the construction and applications of the sensors, using different physical properties. The data presented in this publication have been received using SENSOR LINE PUR experimental sensors (SENSORLINE GmbH., 2010) based on the change of the transparency (the intensity of the light signal) during the deformation. 


\section{Axles Weighing-in-Motion Principles}

The fibre optic weight sensor is the cable consisting of a photoconductive polymer fibres coated with a thin light-reflective layer (Fig. 1(b)). A light conductor is created in such a way that the light cannot escape. If one directs a beam of light to one end of the cable, it will come out from the other end and in this case the cable can be twisted in any manner. To measure the force acting on the cable, the amplitude technology is more appropriated for the measurements based on measuring of the optical path intensity, which changes while pushing on the light conductor along its points.

(a)

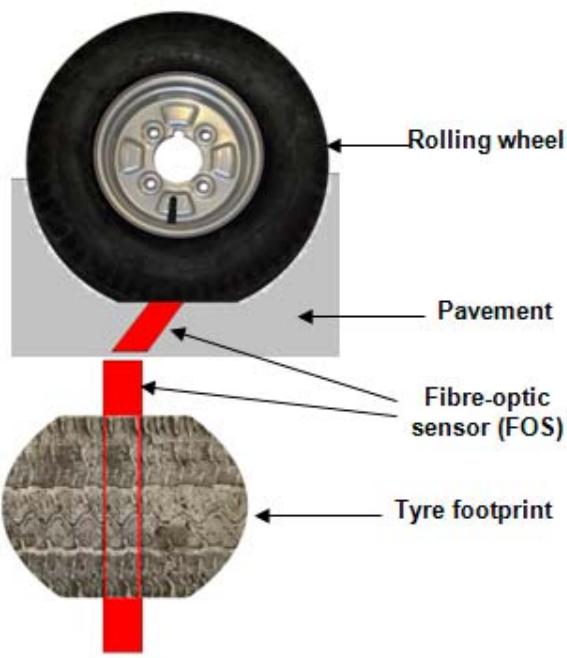

(c)

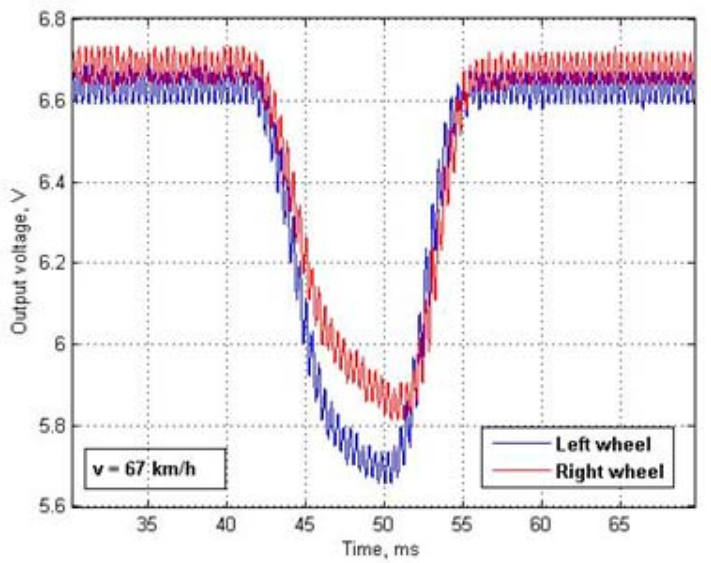

(b)
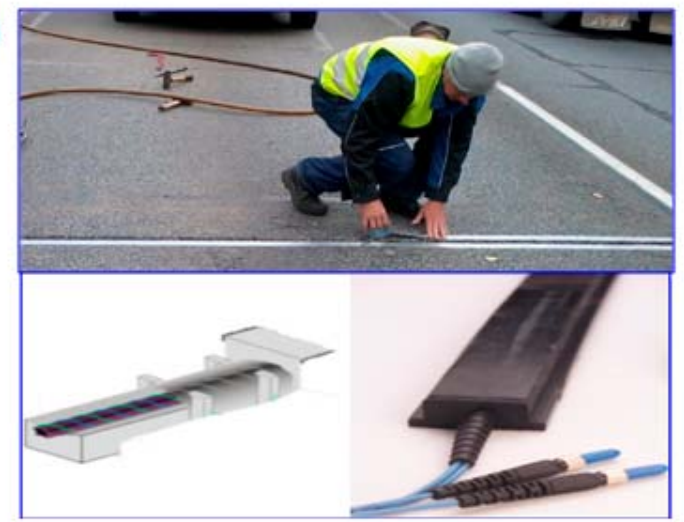

(d)

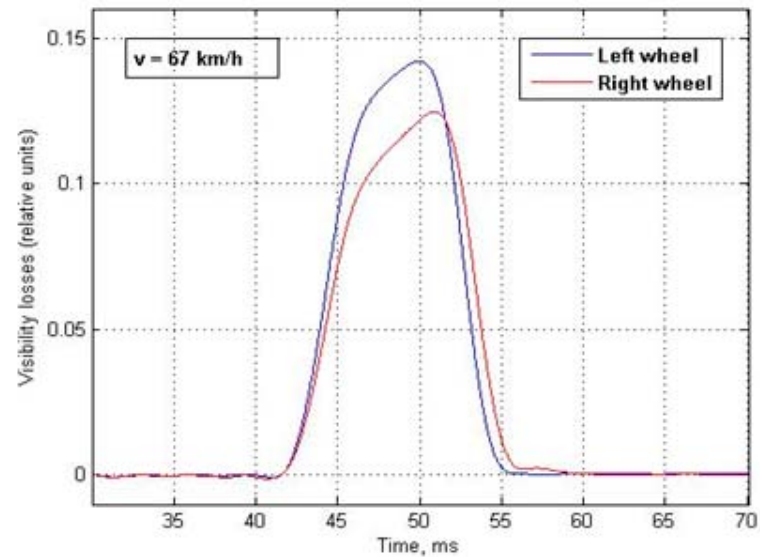

Figure 1. (a) Fibre optic sensor's position against the wheel and tyre footprint, (b) SENSORLINE PUR installation and construction of the sensor, (c) FOS output voltage, (d) Visibility losses as the function of pressure after pre-processing (filtering)

At these points the deflection of a light conductor and reflective coating occurs, that is why the conditions of light reflection inside are changed, and some of it escapes. The greater the load the less light comes from the second end of the light conductor. Therefore the sensor has the unusual characteristic for those, familiar with the strain gauges: the greater the load the lower the output is. Apart from the fact that it is reversed and in addition to this it is non-linear.

In order to avoid the inaccuracy of zero load level we need to exclude the high frequency components from the voltage signal at the output of the sensor's transducer by filtering, as well as to recalculate the voltage signal $\boldsymbol{U}(\boldsymbol{t})$ (Fig. 1(c)) into the relative visibility losses signal $\boldsymbol{V}(\boldsymbol{t})$ (Fig. 1(d)), directly related to the weight pressure on the FOS surface. It can be done by the transformation (1):

$V(t)=\frac{U_{0}-U(t)}{U_{0}}$, 
where $\boldsymbol{U}_{\boldsymbol{0}}$ is the voltage of sensor's output with zero loads. The signal transformation to the relative visibility losses signal $\boldsymbol{V}(\boldsymbol{t})$ gives the possibility to compare signals for different measurements in different conditions.

Fibre optic load-measuring cables are placed in the gap across the road, filled with resilient rubber (Fig. 1(b)). The gap width is $30 \mathrm{~mm}$. Since the sensor width is smaller than the tyre footprint on the surface, the sensor takes only part of the axle weight. Two methods are used in the existing systems to calculate the total weight of the axle (Malla \& etc., 2008; McCall \& Vodrazka, 1997): the Basic Method and the Area Method. The following formula is used to calculate the total weight of the axis using the Basic Method:

$W_{h a}=A_{t} \cdot P_{t}$,

where $\boldsymbol{W}_{\boldsymbol{h} \boldsymbol{a}}$ - weight on half-axle, $\boldsymbol{A}_{\boldsymbol{t}}$ - area of the tyre footprint, $\boldsymbol{P}_{\boldsymbol{t}} \sim \boldsymbol{V}(\boldsymbol{t})-$ air pressure inside the tyre and, according to Newton's $3^{\text {rd }}$ law, it is proportional to the axle weight.

As we can see the exact values of the formula factors are unknown. The area of the tyre footprint is calculated roughly by the length of the output voltage impulse, which, in its turn, depends on the vehicle speed. The Area Method uses the assumption that the area under the recorded impulse curve line, in other words - the integral, characterizes the load on the axle. To calculate the integral, the curve line is approximated by the trapezoid. In this case the smaller the integral - the greater the load. This method does not require knowing the tyre pressure, but it requires the time-consuming on-site calibration. Also, it has to be kept in mind that the time of the tyre crossing the sensor is too small to get an electrical signal of high quality for its further mathematical processing. We use the Area method only for the tyre footprint area definition in (2), but the pressure is measured from the signal amplitude.

\section{Experimental Vehicle Parameters}

There was the set of measurement experiments with the roadside FOS sensors on April, 2012 in Riga, Latvia. Loaded truck (Fig. 2) was preliminary weighed on the weighbridge with the accuracy $<1 \%$.

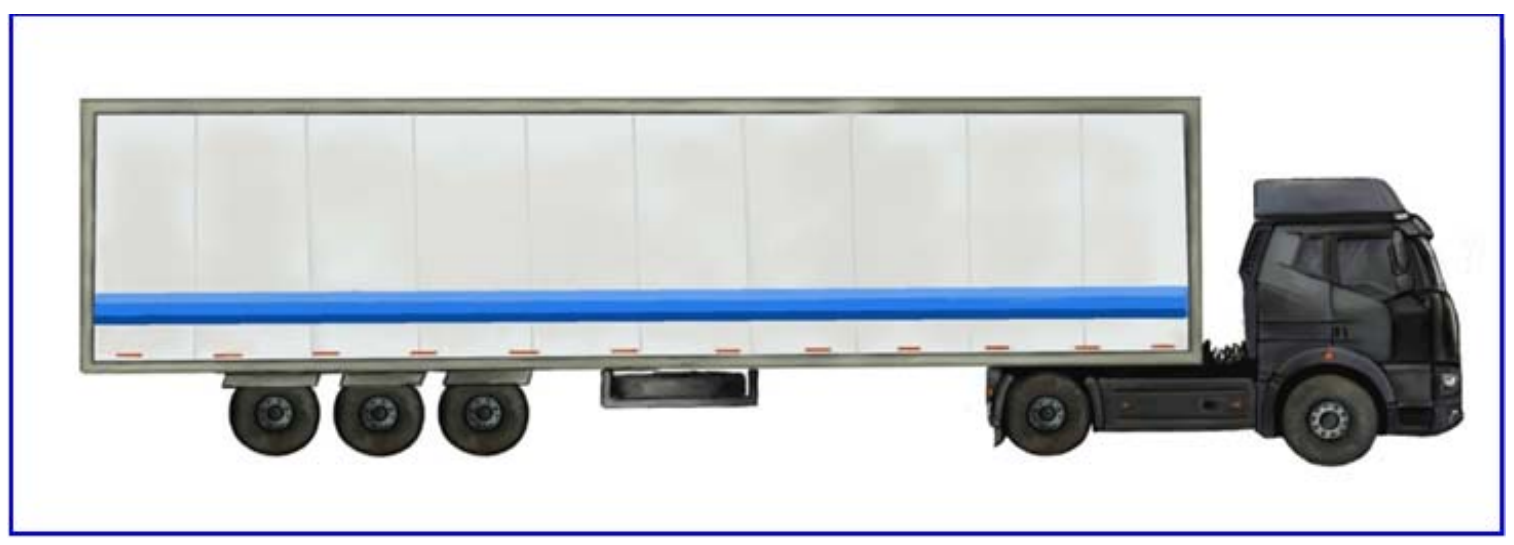

Figure 2. Experimental truck "Volvo FH12" with full load $36900 \mathrm{~kg}$

Table 1. The reference static axle weights

\begin{tabular}{|c|c|c|c|c|c|}
\hline \multicolumn{7}{|c|}{ Date: 20.04.2012 (Air Temperature $+12^{\circ} \mathrm{C}$ ) } \\
\hline Reference axle weight (tons): & 7.296 & 12.619 & 5.509 & 5.641 & 5.844 \\
\hline
\end{tabular}

Reference weights of the separate axles are given in the Table 1. The output signals from FOS sensors for truck speeds $70 \mathrm{~km} / \mathrm{h}$ and $90 \mathrm{~km} / \mathrm{h}$ are demonstrated on Figure 3 . It is evident that the signals 
for the different speeds have been changing by amplitude and the proportion of amplitudes does not fit the axle weights (Fig. 3).
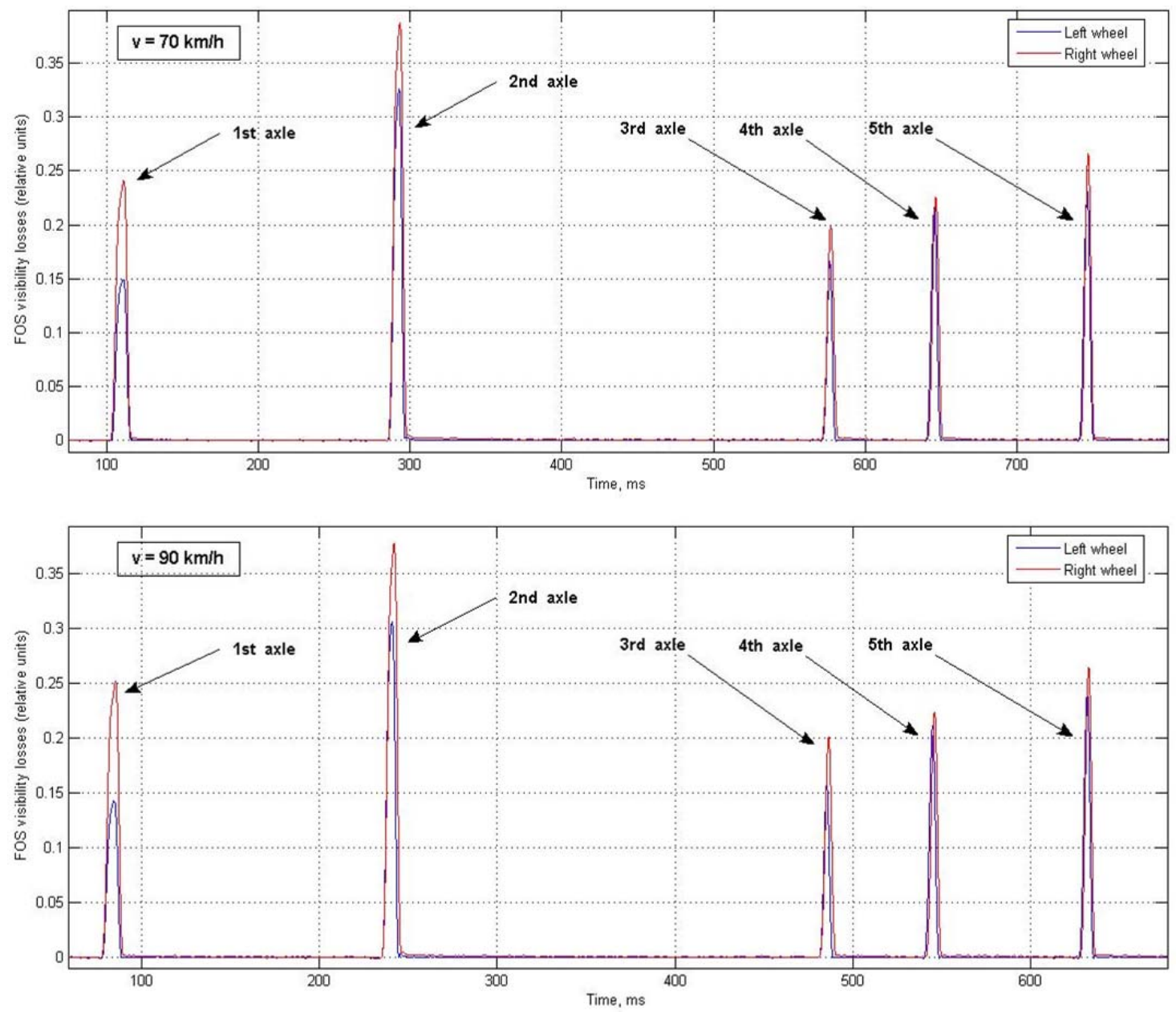

Figure 3. Examples of FOS signals of experimental truck for vehicle speeds $70 \mathrm{~km} / \mathrm{h}$ and $90 \mathrm{~km} / \mathrm{h}$ respectively

The reason of this behaviour may be explained by FOS properties such as weight (pressure) distribution along the sensor length as well as sensor non-linearity and temperature dependence.

\section{Fibre Optic Sensor Properties}

Fibre-optic sensor (SENSORLINE GmbH., 2010) output light intensity changes due to the applied external vertical force were measured using of the optical interface SL MA-110 that was developed by SensorLine GmbH (SENSORLINE GmbH., 2010). Laboratory experiments with varying parameters (temperature, steel plate width and load speed) were made at the Institute of Polymer Mechanics (University of Latvia) with electronically controlled compression machine.

The first experiment examined the load characteristic according to the temperature change: FOS was placed into the tube of the soft thermal insulation material in which chilled carbon dioxide was circulating. The load from a compression machine was applied to the sensor through the tube and a $200 \times 200 \mathrm{~mm}$ square steel plate (Figure 4(a)). It was found during this experiment that the optical response of the FOS was changing due to the warming; and it is important to notice, that no pressure has been applied (Figure 4(b)). 

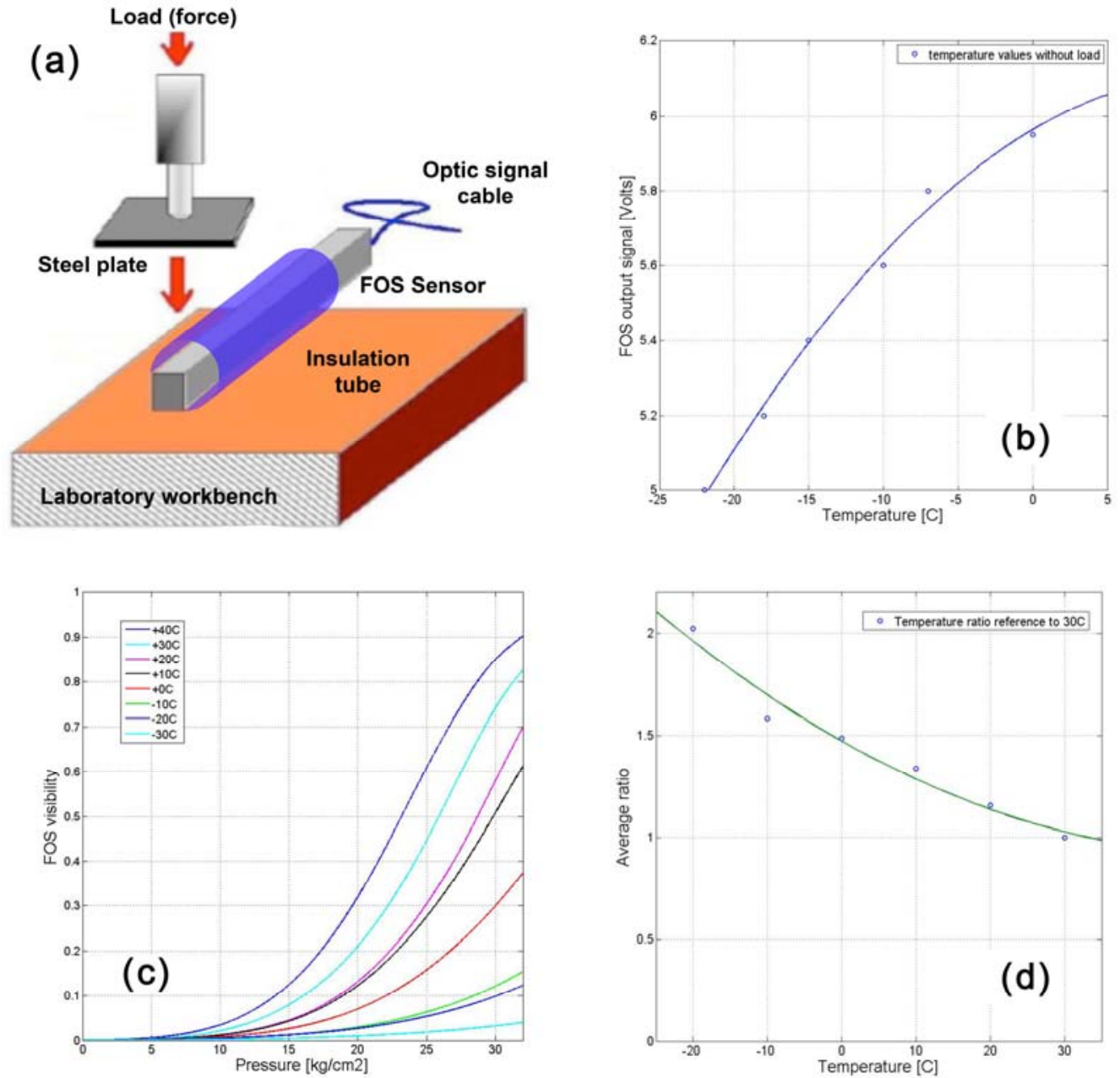

Figure 4. (a) Experimental laboratory equipment scheme, (b) FOS temperature dependence without applying load, (c) FOS load characteristics at different temperatures and (d) Fitted model of FOS various temperature load characteristic ratio values relative to $30^{\circ} \mathrm{C}$ degrees

FOS is permanently installed in the road surface, therefore environment temperature changes affect characteristics of the protective housing rubber (stiffness) and the medium where the light propagates. These changes introduce nonlinear distortions, which together with externally applied pressure on a FOS, are displayed on Figure 4(c). Relations between the load characteristics at the different temperatures are displayed on Figure 4(d). These relations can be conditionally described by polynomial approximation model:

$L C_{T / C]}=L C_{30 / C l} \cdot\left(a_{2} \cdot t^{2}+a_{1} \cdot t+a_{0}\right)$,

where $\boldsymbol{L} \boldsymbol{C}_{T / C]}$ is desired load characteristic at $\mathbf{T}^{\circ} \mathrm{C}$ degrees, $\boldsymbol{L} \boldsymbol{C}_{30[C]}$ is load characteristic at $30^{\circ} \mathrm{C}$ degrees and $\mathbf{a}_{2,1,0}$ are coefficients of least square optimisation calculated from Figure 4(d).

In the real environment tyre footprint width may vary depending on tyre size and inflation pressure, which will result in the different force redistribution. The second experiment shows this dependence (Figure 5(a)), these measurements were made at constant temperature $14^{\circ} \mathrm{C}$ degrees and constant loading speed $20 \mathrm{~mm} / \mathrm{s}$.

Relations between the load characteristics obtained using the different steel plates are displayed on Figure 5(b). These relations can be conditionally described by exponential approximation model: 


$$
L C_{W[m m]}=L C_{200[m m]} \cdot a_{1}\left(1-e^{a_{0} / W}\right),
$$

where $\boldsymbol{L} \boldsymbol{C}_{\boldsymbol{W [ m m ]}}$ is desired load characteristic with $\boldsymbol{W} \mathrm{mm}$ wide plate, $\boldsymbol{L} \boldsymbol{C}_{\mathbf{2 0 0 [ m m}}$ is load characteristic with $200 \mathrm{~mm}$ wide plate and $\boldsymbol{a}_{1,2}$ are coefficients of least square optimisation calculated from Figure 5(b).
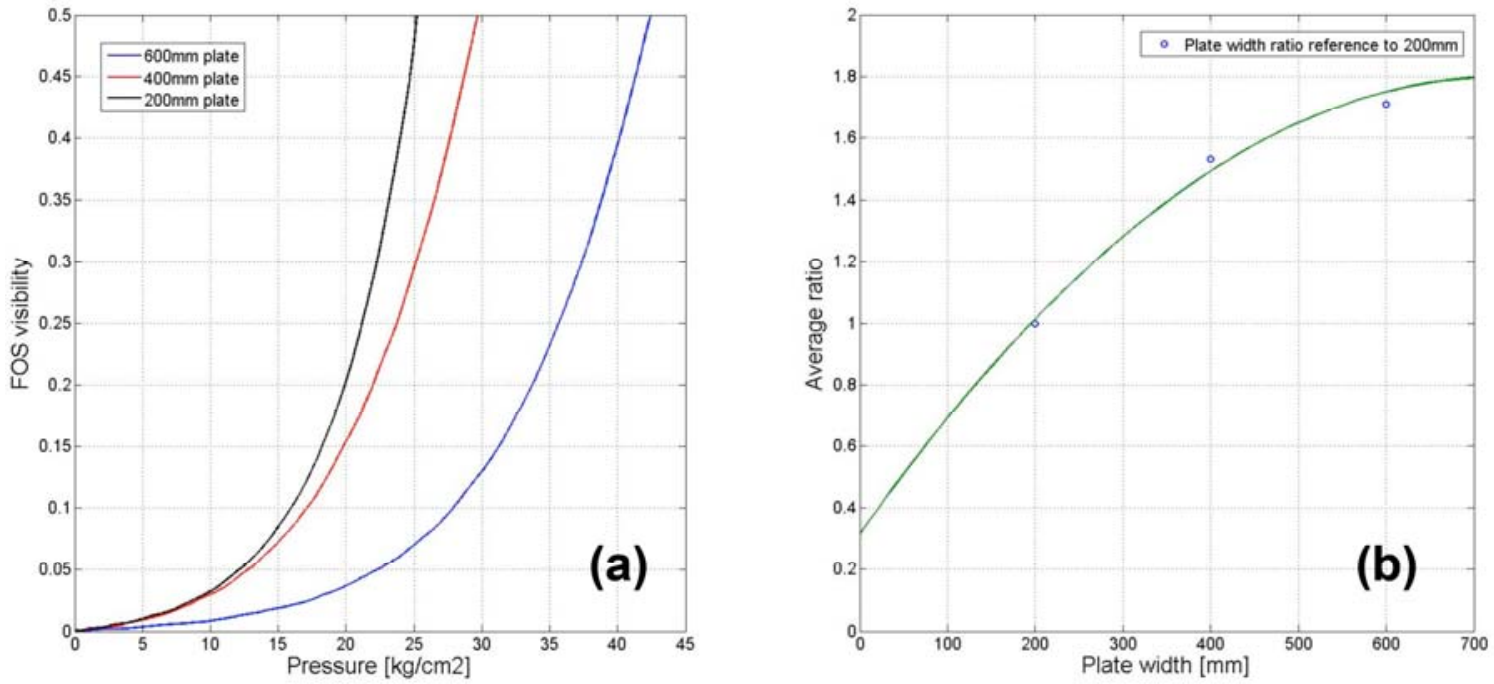

Figure 5. (a) FOS load characteristics with the different steel plate widths and (b) Fitted model of FOS various steel plate width load characteristic ratio values relative to $200 \times 200 \mathrm{~mm}$ steel plate
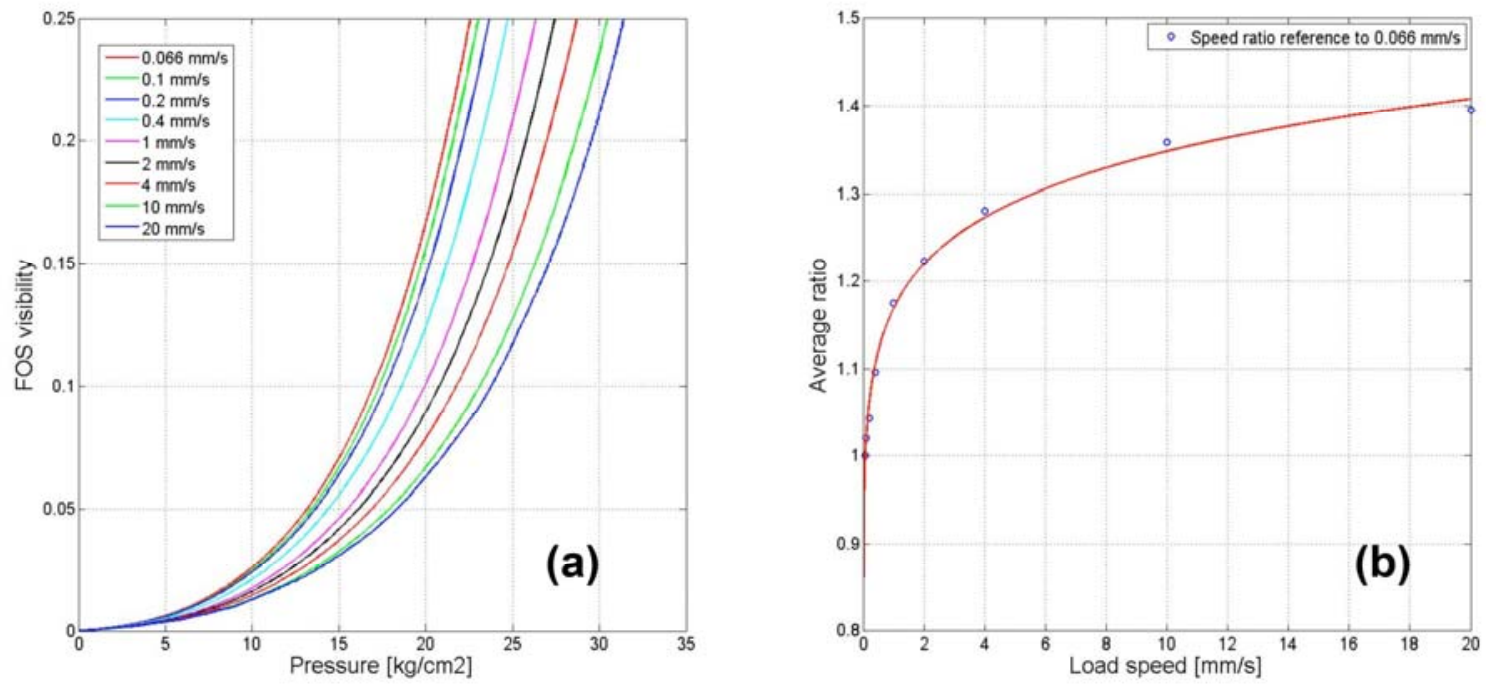

Figure 6. (a) FOS load characteristics at different load speeds and (b) Fitted model of FOS various load speed load characteristic ratio values relative to $0.066 \mathrm{~mm} / \mathrm{s}$ load speed

The vehicles are crossing the FOS at the different speeds and the sensor reaction is different due to its inertia properties. Therefore the third experiment was dedicated to study FOS output signal dependence on applied force at the different speeds (Figure 6(a)): these measurements were made at the constant temperature $17^{\circ} \mathrm{C}$ degrees and the steel plate size $200 \mathrm{~mm}$. Relations between the loads characteristics at the different applied speeds are displayed on Figure 6(b). These relations can be conditionally described by power approximation model:

$L C_{S[m m / s]}=L C_{0.066[m m / s]}\left(a_{1}+S^{a_{0}}\right)$ 
where $\boldsymbol{L} \boldsymbol{C}_{\boldsymbol{X}[\mathrm{mm} / \mathrm{s}]}$ is desired load characteristic at $\boldsymbol{S} \mathrm{mm} / \mathrm{s}, \boldsymbol{L} \boldsymbol{C}_{\mathbf{0 . 0 6 6 / m m} / \mathrm{s}]}$ is load characteristic at $0.066 \mathrm{~mm} / \mathrm{s}$ and $\boldsymbol{a}_{1,0}$ are coefficients of least square optimisation calculated from Figure 6(b).

\section{Vehicle Speed and Tire Contact width Evaluation}

Using FOS A (FOS B) and FOS 1 (FOS 2) symmetric signals, which are shown in Figure 7, it is possible to calculate the speed of each axle, also the truck speed by calculating the average of the values found before. In order to do this, it is necessary to normalize the signals, filter out the noise and obtain symmetrical signal components. Then impulse peak time value of these components will be used in the axle speed calculation. Distance between FOS A and FOS 1 (or FOS B and FOS 2) should be known in advance; in our case it is equal to $3 \mathrm{~m}$ (see Figure 8).

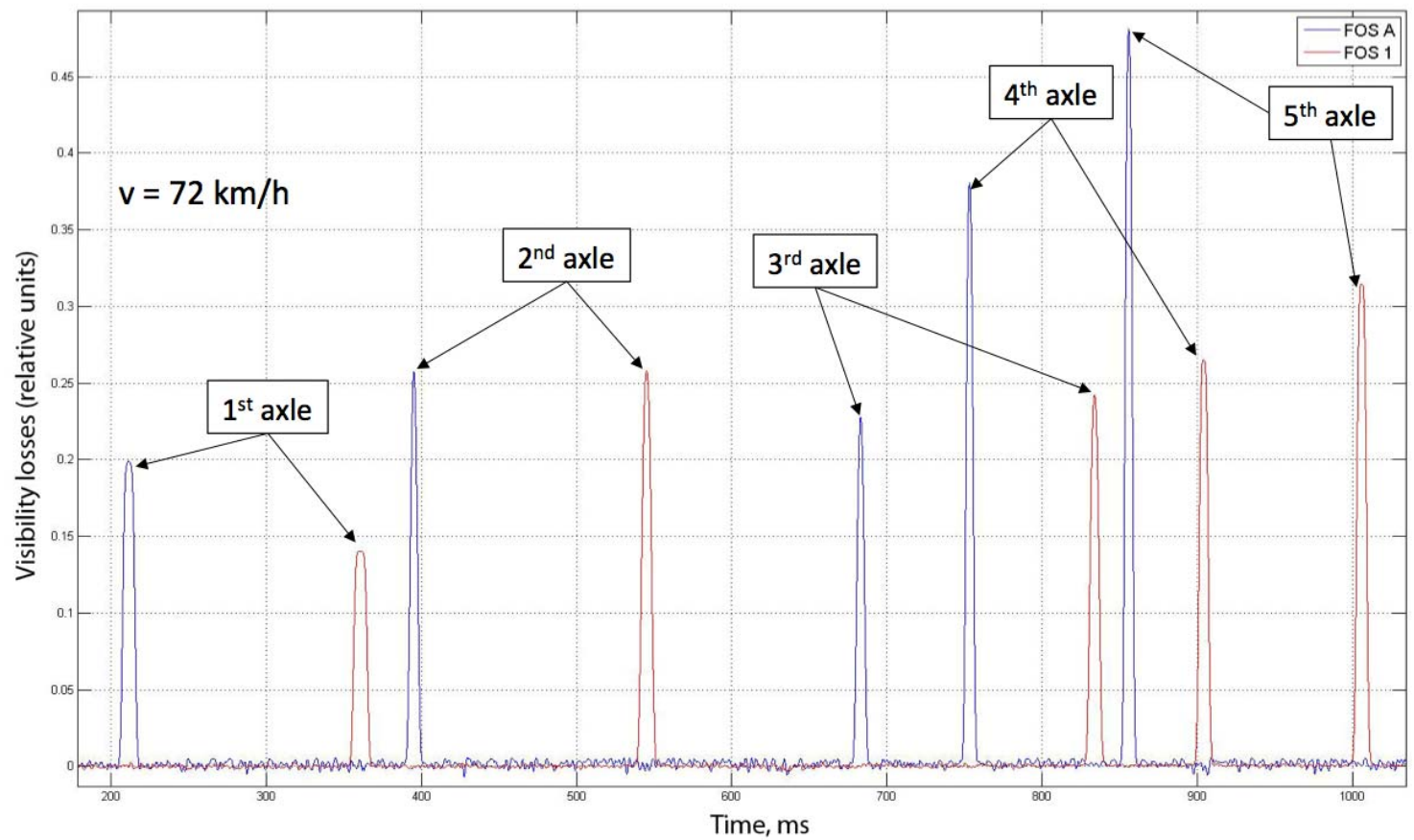

Figure 7. FOS vertical weight component (symmetric) of s1_A, B, 3, 4_70km_27_09_2013 signal

Calculated axle and vehicle speeds, based on the FOS signal peak time of symmetric components, are shown in Table 2.

Table 2. Calculated speed values of s1_A, B, 3, 4_70km_27_09_2013 signal

\begin{tabular}{|c|c|c|c|c|c|c|}
\hline Speed/axle & $1^{\text {st }}$ axle & $2^{\text {nd }}$ axle & $3^{\text {rd }}$ axle & $4^{\text {th }}$ axle & $5^{\text {th }}$ axle & Vehicle \\
\hline Calculated speed $[\mathrm{km} / \mathrm{h}]$ & 72.34 & 72.00 & 71.63 & 71.56 & 71.93 & 71.89 \\
\hline
\end{tabular}

Using FOS 1d and FOS A (or FOS 1), which are shown in Figure 8(a), as well as the symmetric FOS pair signals, it is possible to evaluate left and right tyre footprint widths. In order to do this, it is necessary to normalize the signals, filter out the noise and make linearization of the signals according to the pre-calculated axial velocity and temperature of the FOS.

Then pulse widths of perpendicular and diagonal FOS (see Figure 8(b)) are measured on experimentally chosen level of 0.4 , multiplying this width subtraction by corresponding axle speed will be the evaluation of tyre footprint. 


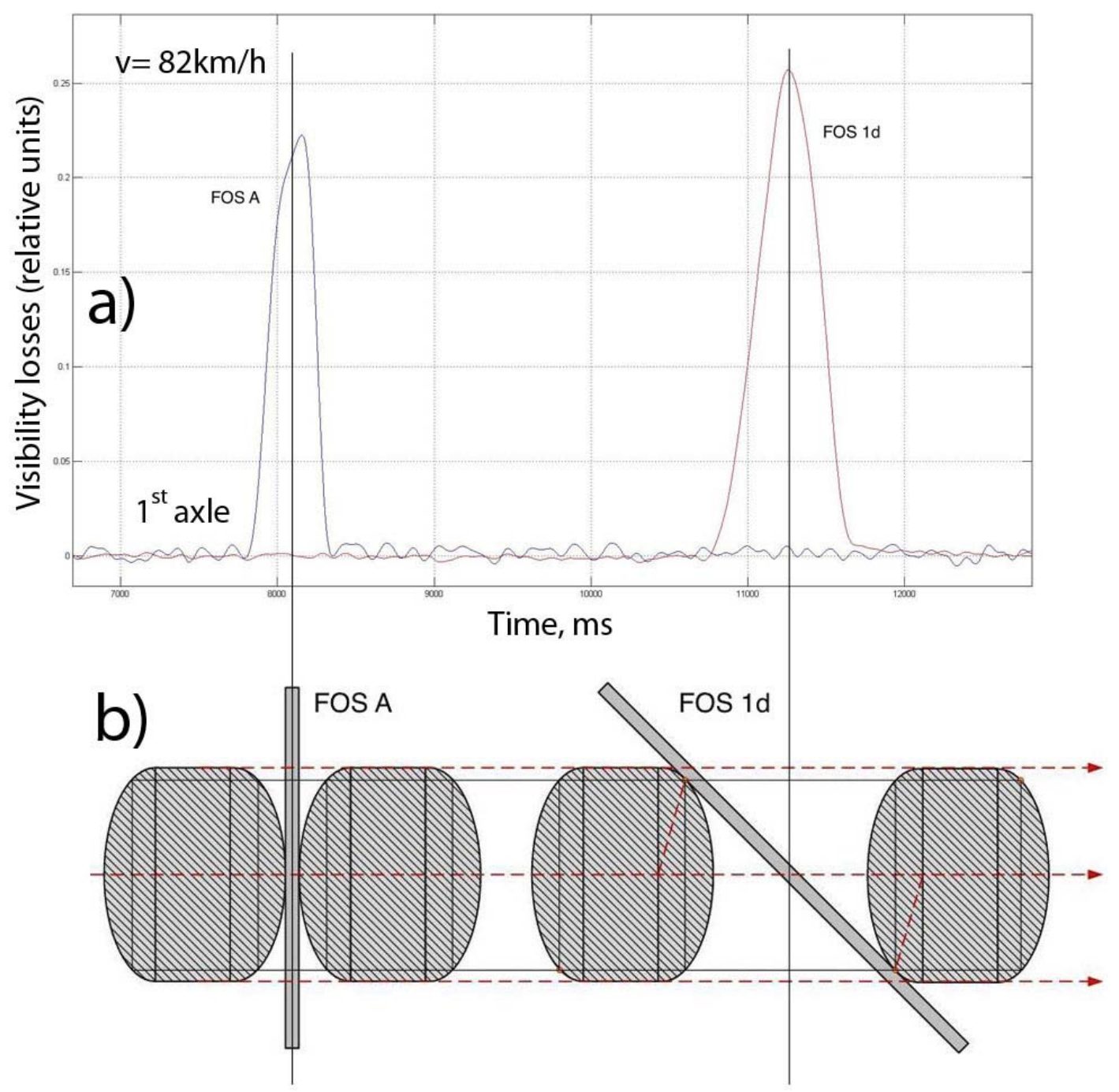

Figure 8. (a) FOS A and FOS 1d filtered s1_A,B,1d,2d_90km_27_09_2013 signal; (b) Tyre footprint interaction with FOS

Table 3. Evaluated tyre footprint width of s1_A, B, 1d, 2d_90km_27_09_2013 signal

\begin{tabular}{|l|c|c|c|c|c|}
\hline Parameter / axle & $1^{\text {st }}$ axle & $2^{\text {nd }}$ axle* & $3^{\text {rd }}$ axle & $4^{\text {th }}$ axle & $5^{\text {th }}$ axle \\
\hline Footprint width [mm] & 315 & $\mathbf{6 8 0}$ & 385 & 385 & 385 \\
\hline $\begin{array}{l}\text { Evaluated footprint } \\
\text { width [mm] }\end{array}$ & 310.317 & $\mathbf{8 9 0 . 6 3 3}$ & 399.993 & $\mathbf{3 7 5 . 2 0 2}$ & $\mathbf{3 8 7 . 9 2 5}$ \\
\hline Error [\%] & $-\mathbf{- 1 . 4 8 7 \%}$ & $\mathbf{3 0 . 9 7 5 \%}$ & $\mathbf{3 . 8 9 4 \%}$ & $\mathbf{- 2 . 5 4 5 \%}$ & $\mathbf{0 . 4 9 9} \%$ \\
\hline
\end{tabular}

* - dual wheels (the distance between two neighbour dual wheels approximately is $40-50 \mathrm{~mm}$ and it cannot be measured exactly)

\section{Tyre Footprint and Weight Estimation}

As it is clearly seen from the expression (2), the $\boldsymbol{A}_{\boldsymbol{t}}$ area of the tyre footprint should be known to calculate the axle weight by the registered FOS signal (Batenko \& etc., 2011). The form of the signal is non-symmetric and sufficiently distorted by the rolling process of the wheel on the road surface (see Figure 9(a)). 

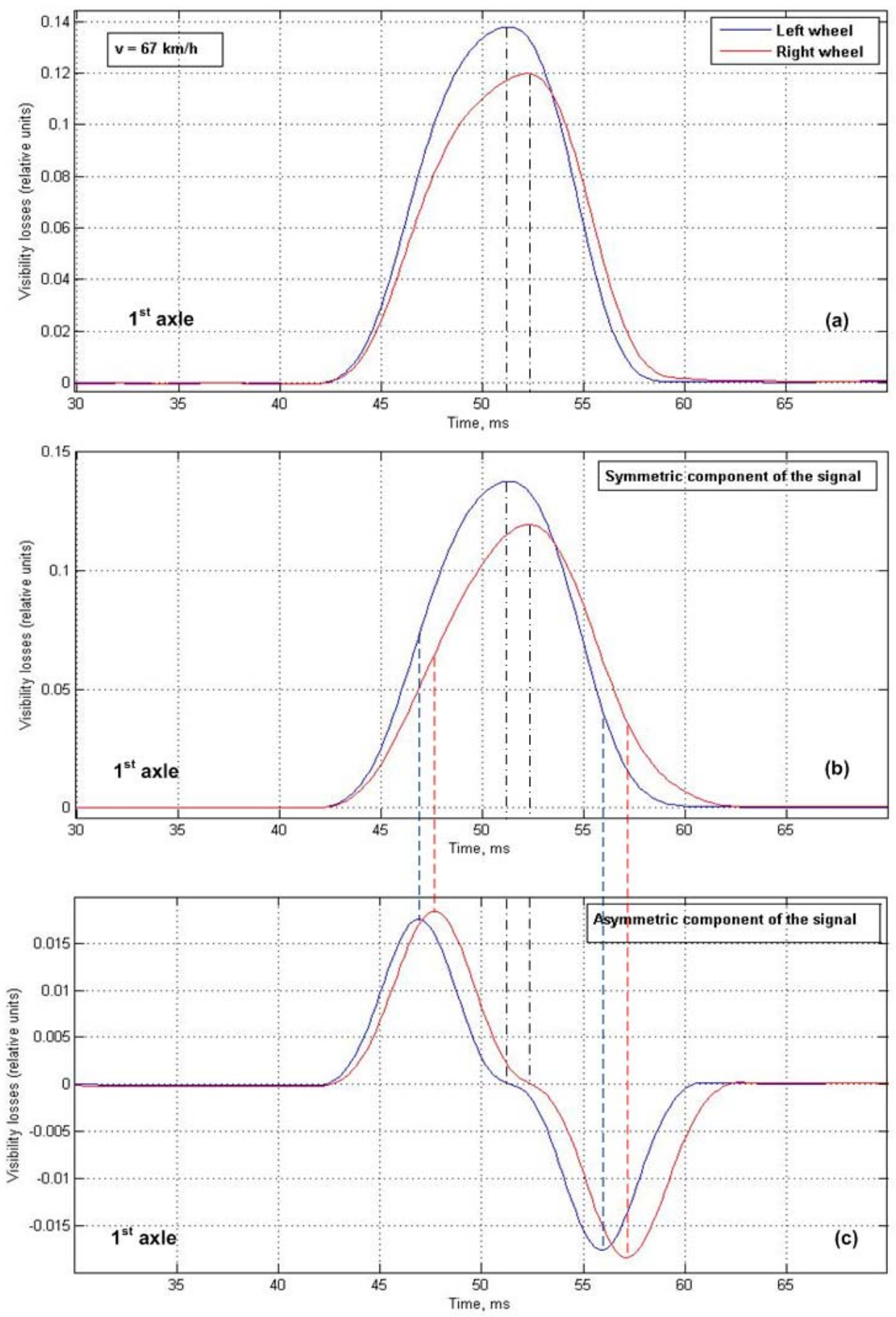

Figure 9. (a) FOS output signal in the form of visibility losses (formula 1), (b) Approximated vertical weight component (symmetric), and (c) Approximated asymmetric component depending on horizontal velocity and friction (Krasnitsky, 2012)

One of the possible explanations of the signal waveform distortion is the idea about the common interaction of two factors (Krasnitsky, 2012): vertical dead weight gravity of conditionally immovable wheel (according to wheel geometry it must be symmetric, see Figure 9(b)), and the force of friction (it depends on the pavement and tyre properties, wheel's speed and weight, and its expected waveform is asymmetric, see Figure 9(c)). The problem of the decomposition of the non-symmetric signal in 2 parts (symmetric and asymmetric) can be solved by the polynomial approximation using the least square method and the further grouping of members with even and odd powers separately or by standard even-odd decomposition of the signal on finite window (Mesco, 1984; Vinay \& etc., 2006). 


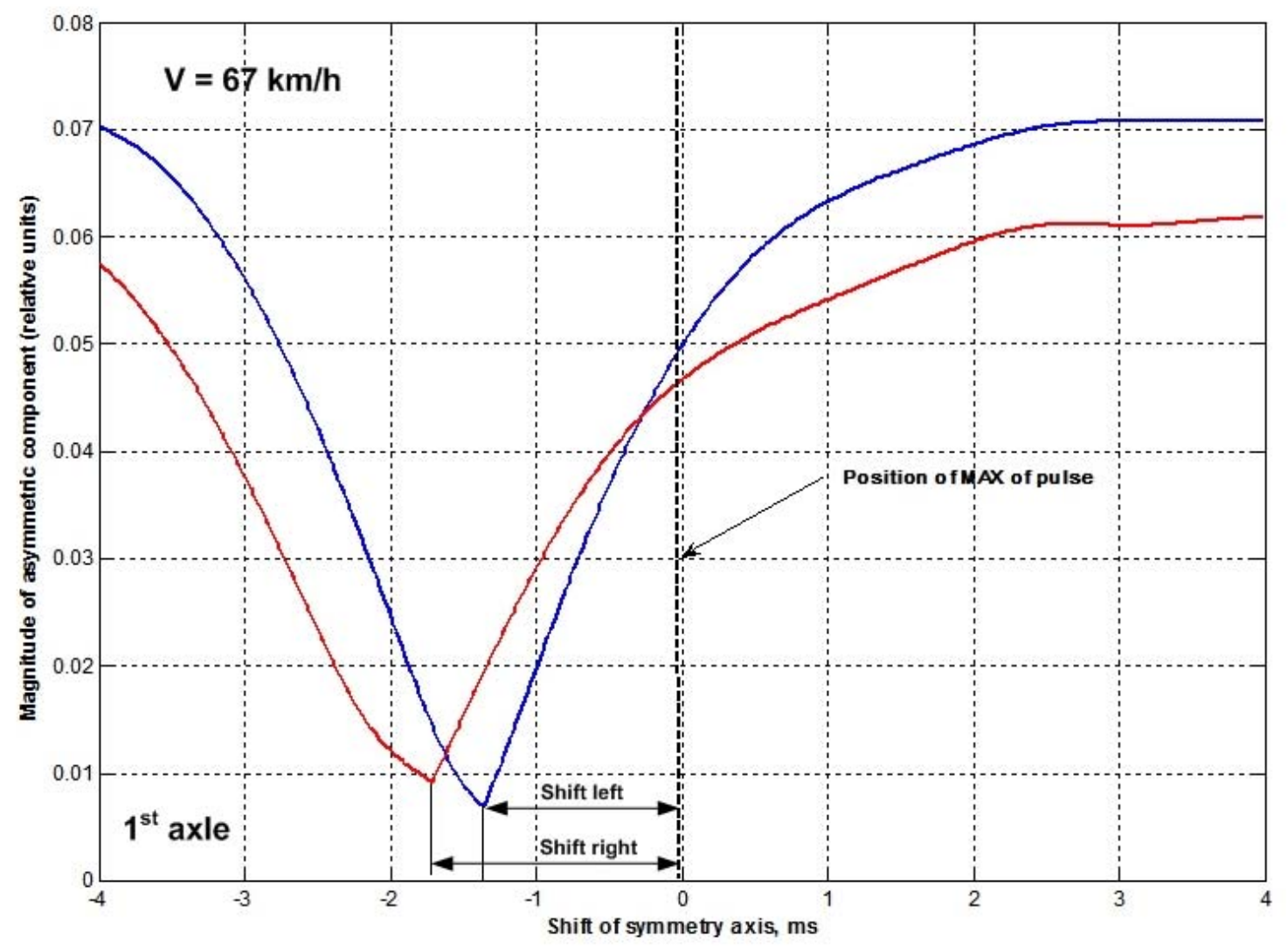

Figure 10. Approximated asymmetric component magnitude as the function on symmetry axis shift from the maximum of the pulse

On the other hand, by assumption that the vehicle moves uniformly and all forces maximally compensate each other, we can accept that the friction force is as minimal as possible (rolling friction only without sliding friction). It is possible to minimize the friction component magnitude moving the axis of symmetry before the pulse (see Figure 10). This dependence is obtained by calculation of the maximum (magnitude) of asymmetric component of the signal changing the shift between maximum of initial pulse form and location of symmetry axis. It will be minimal at the position conditionally named as the "mass centre" of the pulse (see Figure 11(a)).

The waveform of the friction component on Figure 11(b)) sufficiently differs from the same on Figure 9(c). Two maximums and two minimums clearly locate the characteristic points for the tire footprint estimation in the elliptic approximation (see Figure 11(c)).

Now the problem of the tyre footprint area estimation may be solved. Multiplying the impulse length by the speed of the wheel we can calculate the length of the footprint. In the considered examples (Figures 9 and 11) it is $\boldsymbol{L}_{\text {left }}=0.1905 \mathrm{~m}$ and $\boldsymbol{L}_{\text {right }}=0.1976 \mathrm{~m}$. It agrees with another data for the wheel R22.5 and tyre width of $315 \mathrm{~mm}$ for the $1^{\text {st }}$ axle.

Applying the above-mentioned approach to another vehicle's axles and wheels we can estimate the length and form of each tyre footprint. Of course, the width of the $2^{\text {nd }}$ axle's tyre we consider as double (double wheels for Volvo FH12 vehicle's the $2^{\text {nd }}$ (motor) axle).

Full data of footprint lengths for experimental cargo vehicle (see Figure 2, 11, 12 and Table 1) are the following: the left side wheels lengths are $\boldsymbol{L}_{\boldsymbol{L} 12345}=\left\{\begin{array}{lllll}0.1905 & 0.1652 & 0.1278 & 0.1354 & 0.1379\end{array}\right\}$ meters, and the right side wheels lengths are $\boldsymbol{L}_{\boldsymbol{R} 12345}=\left\{\begin{array}{lllll}0.1976 & 0.1799 & 0.1509 & 0.1449 & 0.1356\end{array}\right\}$ meters. The difference between the lengths of each wheel can be explained by the fact that the $2^{\text {nd }}$ axle has the double-wheel, the trailer tyres but (axles No 3-5) width is $385 \mathrm{~mm}$. 

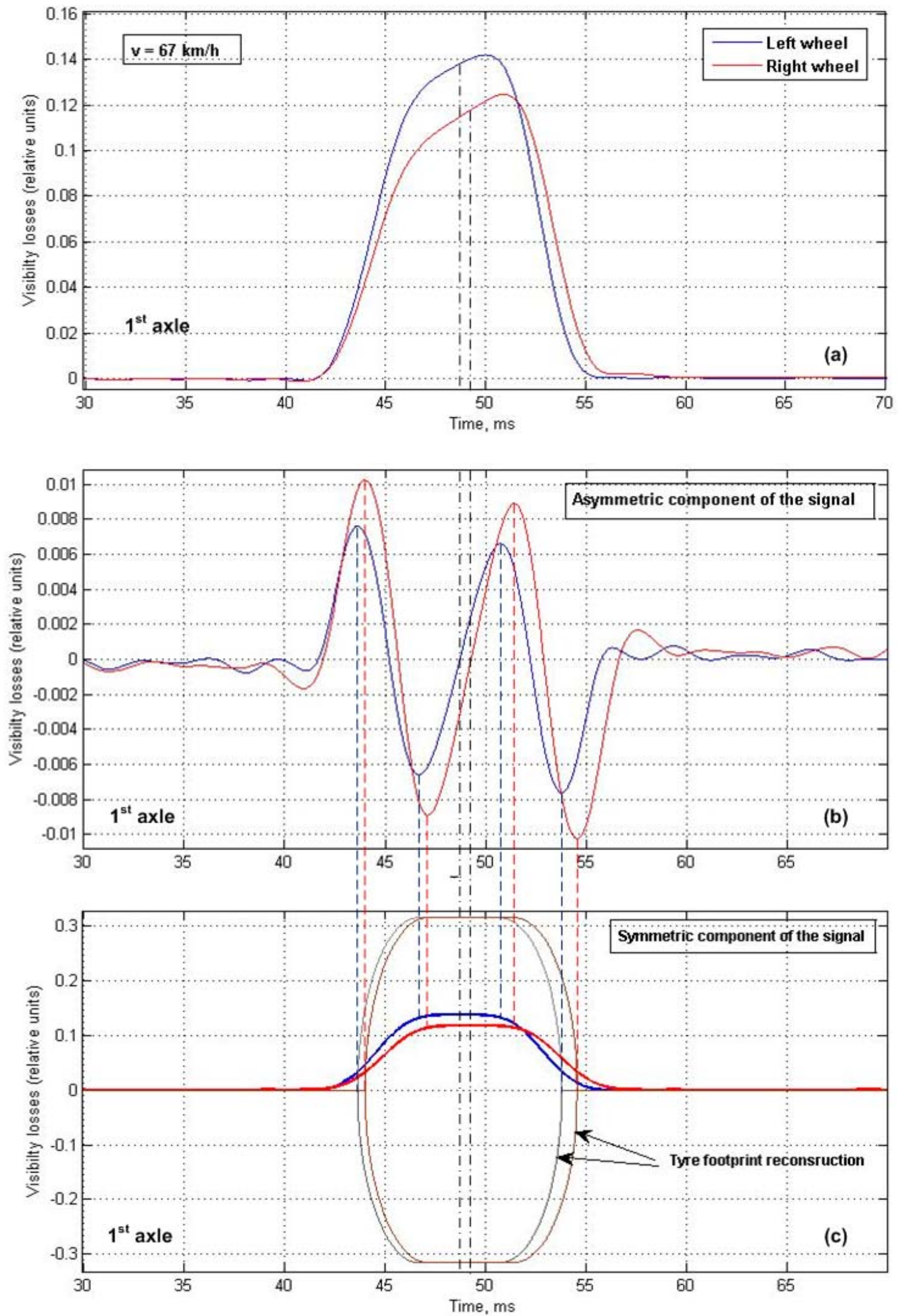

Figure 11. (a) FOS output signal in the form of visibility losses in dimensionless units, (b) Approximated vertical weight component (symmetric), (c) Approximated asymmetric component and tire footprint reconstruction in case of minimal friction condition 

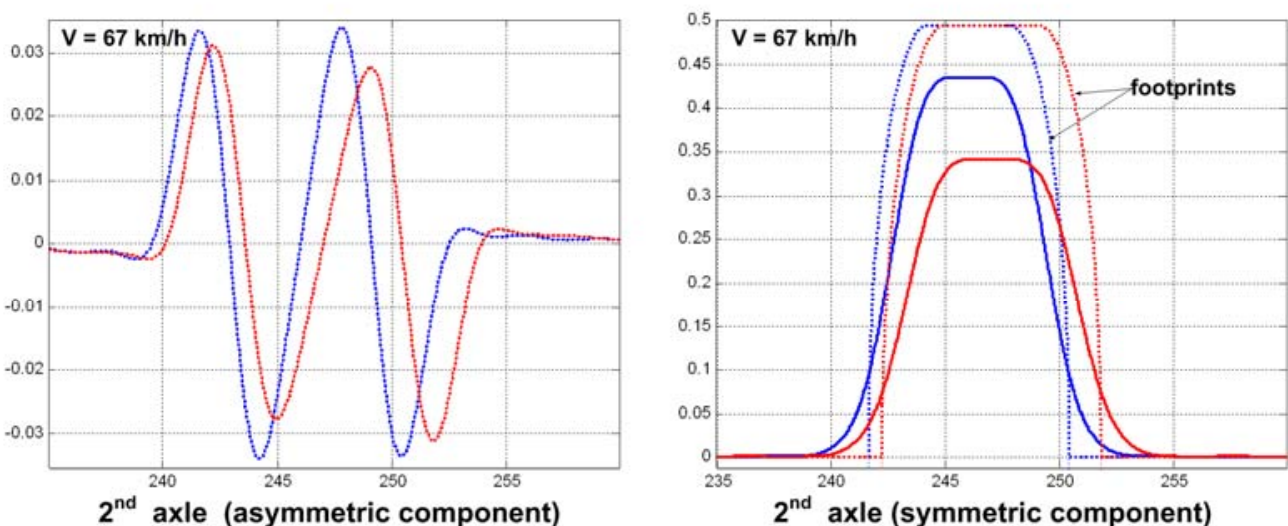

$2^{\text {nd }}$ axle (symmetric component)
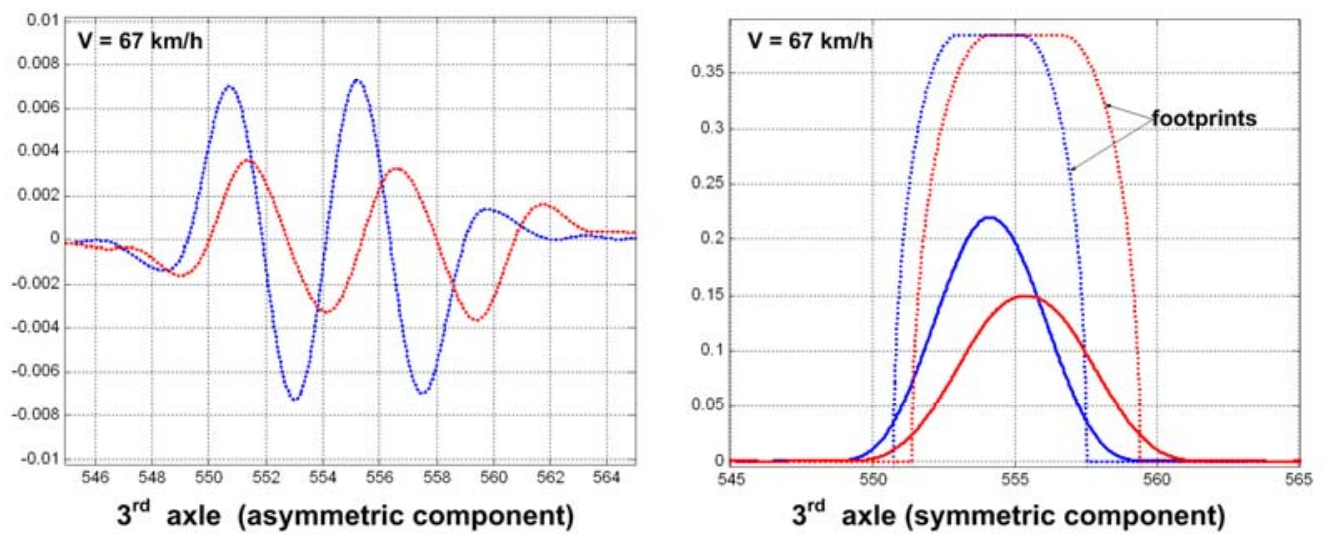

$3^{\text {rd }}$ axle (symmetric component)

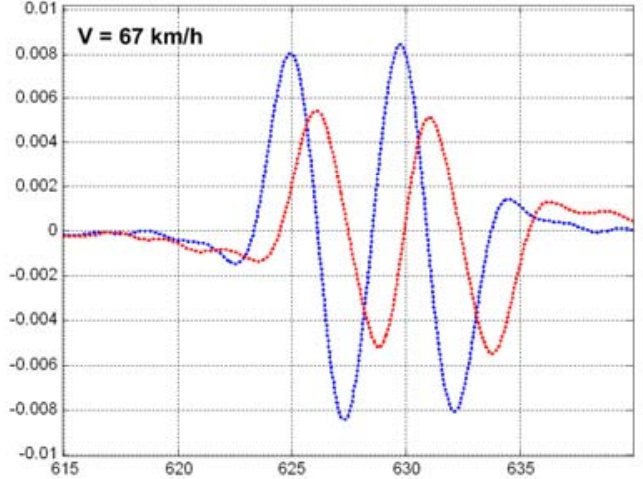

$4^{\text {th }}$ axle (asymmetric component)

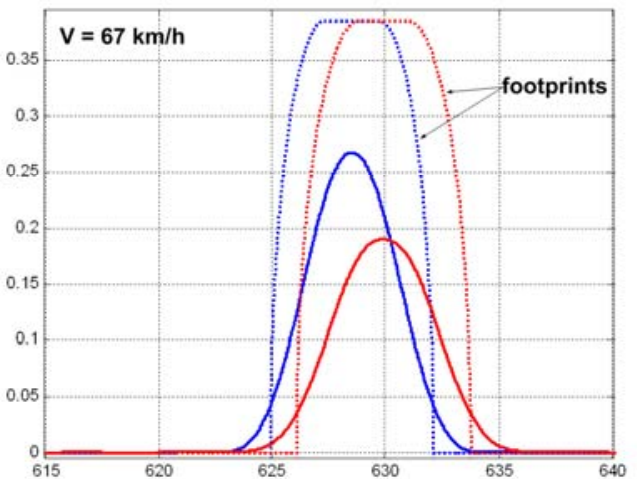

$4^{\text {th }}$ axle (symmetric component)
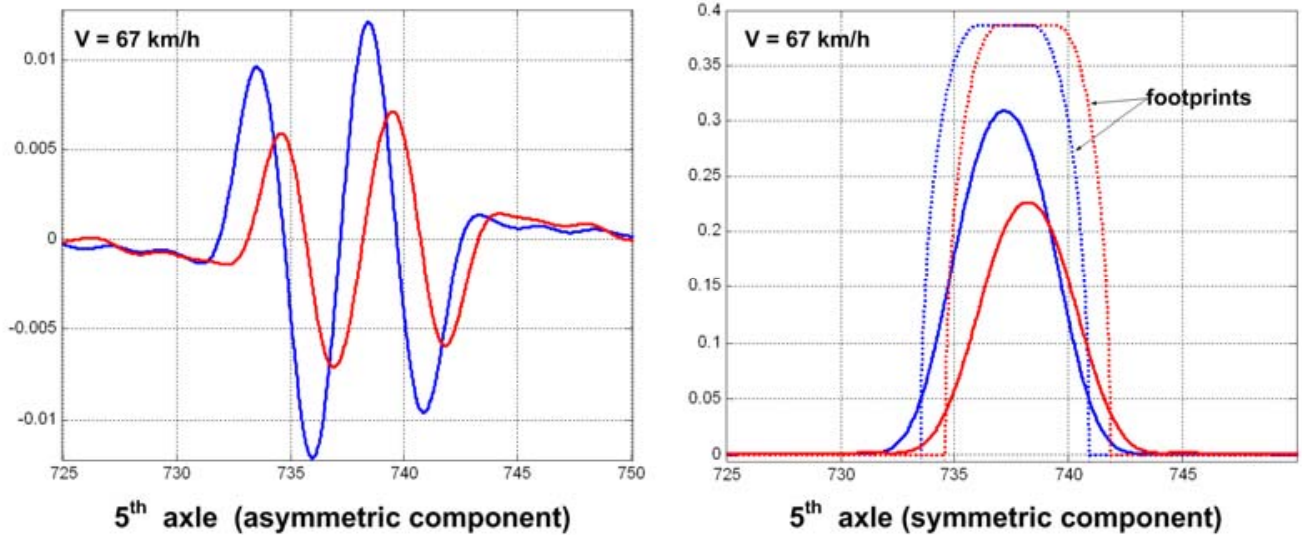

$5^{\text {th }}$ axle (symmetric component)

Figure 12. The results of axle's signals deconvolution on symmetric (from the right) and asymmetric (from left) components for the $2^{\text {nd }}, 3^{\text {rd }}, 4^{\text {th }}$ and $5^{\text {th }}$ axle and the form of footprint reconstruction (half of area) respectively 
Applying the sensors signal processing algorithm together with the of estimation of the tyre footprint area and approximation of the nonlinear characteristics of the FOS (Figures 4, 5 and 6) for the suitable range of temperatures, it is possible to estimate the following weights of axles (Table 4):

Table 4. The results of the axle weight estimation and errors for the different measurements at the speeds $10-90 \mathrm{~km} / \mathrm{h}$ (two sets of measurements per speed bin)

\begin{tabular}{|c|c|c|c|c|c|c|}
\hline \multicolumn{7}{|c|}{ Date: 20.04.2012 (Air Temperature $+12^{\circ} \mathrm{C}$ ) } \\
\hline & n axle's weight (tons): & 7.296 & 12.619 & 5.509 & 5.641 & 5.844 \\
\hline \multicolumn{7}{|c|}{ Speed: $10 \mathrm{~km} / \mathrm{h}$} \\
\hline No & Parameter: & $1^{\text {st }}$ axle & 2nd axle & 3rd axle & 4th axle & 5th axle \\
\hline \multirow{2}{*}{1} & Axle's weight (tons) & 7.3392 & 12.7267 & 4.7930 & 5.0592 & 5.8173 \\
\hline & Error $(\%)$ & $0.589 \%$ & $0.855 \%$ & $-12.994 \%$ & $-10.317 \%$ & $-0.453 \%$ \\
\hline \multirow{2}{*}{2} & Axle's weight (tons) & 7.2190 & 14.0050 & 4.6014 & 5.1721 & 6.5539 \\
\hline & Error $(\%)$ & $-1.058 \%$ & $10.985 \%$ & $-16.472 \%$ & $-8.316 \%$ & $12.152 \%$ \\
\hline \multicolumn{7}{|c|}{ Speed: $20 \mathrm{~km} / \mathrm{h}$} \\
\hline \multirow{2}{*}{1} & Axle's weight (tons) & 7.1375 & 12.9337 & 5.3205 & 6.2553 & 6.5012 \\
\hline & Error $(\%)$ & $-2.176 \%$ & $2.496 \%$ & $-3.417 \%$ & $10.885 \%$ & $11.251 \%$ \\
\hline \multirow{2}{*}{2} & Axle's weight (tons) & 7.2929 & 13.5535 & 4.4927 & 4.8372 & 5.6539 \\
\hline & Error $(\%)$ & $-0.046 \%$ & $7.408 \%$ & $-18.445 \%$ & $-14.253 \%$ & $-3.248 \%$ \\
\hline \multicolumn{7}{|c|}{ Speed: $50 \mathrm{~km} / \mathrm{h}$} \\
\hline \multirow{2}{*}{1} & Axle's weight (tons) & 7.5824 & 11.9901 & 5.3806 & 5.4392 & 5.5499 \\
\hline & Error $(\%)$ & $3.921 \%$ & $-4.982 \%$ & $-2.327 \%$ & $-3.582 \%$ & $-5.029 \%$ \\
\hline \multirow{2}{*}{2} & Axle's weight (tons) & 7.4452 & 12.4781 & 5.1152 & 5.3775 & 5.6148 \\
\hline & Error $(\%)$ & $2.042 \%$ & $-1.114 \%$ & $-7.144 \%$ & $-4.676 \%$ & $-3.918 \%$ \\
\hline \multicolumn{7}{|c|}{ Speed: $70 \mathrm{~km} / \mathrm{h}$} \\
\hline \multirow{2}{*}{1} & Axle's weight (tons) & 7.5129 & 12.1787 & 5.2473 & 5.6684 & 5.6978 \\
\hline & Error $(\%)$ & $2.969 \%$ & $-3.487 \%$ & $-4.746 \%$ & $0.482 \%$ & $-2.497 \%$ \\
\hline \multirow{2}{*}{2} & Axle's weight (tons) & 7.4754 & 12.4669 & 5.2623 & 5.7398 & 5.8544 \\
\hline & Error $(\%)$ & $2.455 \%$ & $-1.204 \%$ & $-4.474 \%$ & $1.747 \%$ & $0.183 \%$ \\
\hline \multicolumn{7}{|c|}{ Speed: $90 \mathrm{~km} / \mathrm{h}$} \\
\hline \multirow{2}{*}{1} & Axle's weight (tons) & 7.3327 & 12.8335 & 5.0597 & 5.3737 & 5.6183 \\
\hline & Error (\%) & $0.499 \%$ & $1.702 \%$ & $-8.152 \%$ & $-4.744 \%$ & $-3.859 \%$ \\
\hline \multirow{2}{*}{2} & Axle's weight (tons) & 7.5990 & 12.0713 & 5.1834 & 5.6570 & 5.8492 \\
\hline & Error $(\%)$ & $4.149 \%$ & $-4.338 \%$ & $-5.907 \%$ & $0.278 \%$ & $0.094 \%$ \\
\hline
\end{tabular}

As it can be seen from the Table 4, the most preferred for the measurements are the velocity ranges from $50 \mathrm{~km} / \mathrm{h}$ and above: the measurement errors of the axle loads do not exceed $10 \%$, which is consistent with the problem of the pre-selection of the overloaded vehicles. The dynamics of vehicle breaking or acceleration is more visible at the low velocities. It can seriously distort the waveform of asymmetric friction component and change characteristic points for tyre footprint estimation. The source of the relatively big measurement errors at the low velocities are the distortion and footprint area reconstruction errors because of the vertical oscillations of the dynamic motion of the vehicle, whose amplitudes are smaller at the higher speeds.

Taking into account the properties of each individual sensor, the calibration of FOS should be conducted twice: at first in the laboratory (load characteristics in the temperature range from $-20^{\circ} \mathrm{C}$ to $+30^{\circ} \mathrm{C}$ ), and, secondly, after installing the sensor in the road surface using the vehicles with allowed but known weight.

\section{Conclusions}

Fibre-optic sensors (FOS) are mainly used as the vehicle detectors because of the complicated dependence of a set of factors (sensor's surface temperature, area of impact (vehicle's tyre width), the speed of loading, and vehicle velocity). The set of input parameters made relatively problematic the task of weigh-in-motion using FOS. The results of the present research demonstrate that the factors mostly impacting the FOS measurement accuracy can be investigated and included into the axle weight calculations. 
An idea to normalize the FOS output voltage by the sensor visibility losses (changing from 1 to 0 ) parameter helps to avoid the influence of the static voltage source instability as well as the conditions of sensor installation into the pavement. Each instantaneous measured value of the rolling wheel is independent here from the output voltage for the unloaded sensor. Also, the static part of the temperature dependence is compensated by this way.

An innovative approach to decompose each wheel response into the gravity (symmetric) and the rolling friction (asymmetric) components near the "mass centre" of the pulse, leads to the possibility of tyre footprint area estimation and weight calculation based on mixed Basic and Area method. Preliminary results of the proposed method for WIM using FOS demonstrates the accuracy of measurements are in range of less than $10 \%$ of the measured weight. It is sufficient for the problem of overloaded vehicles pre-selection.

The experimental results show that the range of the vehicles velocity from 50 to $90 \mathrm{~km} / \mathrm{h}$ seems more appropriate for WIM based on fibre-optic sensors. From the authors point of view, using the additional signal processing efforts, it is possible to achieve the consistent accuracy level not only at the high speeds (above $50 \mathrm{~km} / \mathrm{h}$ ), but also at the low speeds $(10-50 \mathrm{~km} / \mathrm{h})$. We mean $\mathrm{B}+(7)$ according to COST 323 for the high speeds and D2 according to OIML R134 for the low speeds (O'Brien \& Jacob, 1998).

\section{Acknowledgements}

This research was granted by ERDF funding, project "Fiber Optic Sensor Applications for Automatic Measurement of the Weight of Vehicles in Motion: Research and Development (2010-2013)", No. 2010/0280/2DP/2.1.1.1.0/10/APIA/VIAA/094, 19.12.2010.

\section{References}

1. Batenko, A., Grakovski, A., Kabashkin, I., Petersons, E., Sikerzhicki, Y. (2011). Weight-in-Motion (WIM) Measurements by Fiber Optic Sensor: Problems and Solutions. Transport and Telecommunication, 12(4), 27-33.

2. Krasnitsky, Y. (2012). Transient Response of a Small-Buried Seismic Sensor. Computer Modelling and New Technologies, 16 (4), 33-39.

3. Malla, R.B., Sen, A., Garrick, N.W. (2008). A Special Fiber Optic Sensor for Measuring Wheel Loads of Vehicles on Highways. Sensors, 8, 2551-2568.

4. McCall, B., Vodrazka, W., Jr. (1997). States' successful practices weigh-in-motion handbook. Washington, DC.: Federal Highway Administration.

5. Mesco, A. (1984). Digital Filtering: Applications in Geophysical Exploration for Oil, v. 1-2. Budapest: Academiai Kiado.

6. Mimbela, L.-E.Y., Pate, J., Copeland, S., Kent, P. M., Hamrick, J. (2003). Applications of Fiber Optic Sensors in Weigh-in-Motion (WIM) Systems for monitoring truck weights on pavements and structures. Final report on research project (158 p.). Las Cruces, New Mexico, USA: New Mexico State University.

7. O'Brien, E. J., Jacob, B. (1998). European Specification on Vehicle Weigh-in-Motion of Road Vehicles. In Proceedings of the $2^{\text {nd }}$ European Conference on Weigh-in-Motion of Road Vehicles (pp. 171-183). Luxembourg: Office for Official Publications of the European Communities.

8. SENSORLINE GmbH.(C) Sensor Line). (2010). SPT Short Feeder Spliceless Fiber Optic Traffic Sensor: product description. Retrieved January 7, 2011, from http://sensorline.de/home/pages/downloads.php

9. Teral, S.R. (1998). Fiber optic weigh-in-motion: looking back and ahead. Optical Engineering, 3326, $129-137$.

10. Vinay, K.I., Proakis, John G. (2006). Digital Signal Processing Using MATLAB. Thomson Learning. 